\title{
Generation of Dopaminergic Neurons in the Adult Brain from Mesencephalic Precursor Cells Labeled with a nestin-GFP Transgene
}

\author{
Kazunobu Sawamoto, 1,2,3 Naoyuki Nakao,4 Koji Kakishita,4 Yuto Ogawa, ${ }^{1,3,5}$ Yoshiaki Toyama, ${ }^{4}$ \\ Atsuyo Yamamoto, ${ }^{1,3}$ Masahiro Yamaguchi, ${ }^{6}$ Kensaku Mori, ${ }^{6}$ Steven A. Goldman, ${ }^{7}$ Toru Itakura, ${ }^{2,4}$ and \\ Hideyuki Okano ${ }^{1,3,8}$ \\ ${ }^{1}$ Division of Neuroanatomy, Department of Neuroscience, Biomedical Research Center, Osaka University Graduate \\ School of Medicine, Suita, Osaka 565-0871, Japan, 2Strategic Promotion System for Brain Science, The Japanese \\ Ministry of Education, Science, Sports, Culture, and Technology, Chiyoda-ku, Tokyo 100-8966, Japan, ${ }^{3}$ Core Research \\ for Evolutional Science and Technology, Japan Science and Technology Corporation, Kawaguchi, Saitama 332-0012, \\ Japan, ${ }^{4}$ Department of Neurological Surgery, Wakayama Medical College, Wakayama 641-0012, Japan, 5epartment of \\ Orthopaedic Surgery, Keio University School of Medicine, Shinjuku, Tokyo 160-8582, Japan, ${ }^{6}$ Department of Physiology, \\ Graduate School of Medicine, University of Tokyo, Bunkyo-ku, Tokyo 113-0033, Japan, ${ }^{7}$ Department of Neurology and \\ Neuroscience, Cornell University Medical Center, New York, New York 10021, and 8Department of Physiology, Keio \\ University School of Medicine, Shinjuku, Tokyo 160-8582, Japan
}

\begin{abstract}
Mesencephalic precursor cells may one day provide dopaminergic neurons for the treatment of Parkinson's disease. However, the generation of dopaminergic neurons from mesencephalic precursors has been difficult to follow, partly because an appropriate means for recognizing mesencephalic ventricular zone precursors has not been available. To visualize and isolate mesencephalic precursor cells from a mixed population, we used transgenic mice and rats carrying green fluorescent protein (GFP) cDNA under the control of the nestin enhancer. nestin-driven GFP was detected in the mesencephalic ventricular zone, and it colocalized with specific markers for neural precursor cells. In addition, data from flow-cytometry indicated that Prominin/CD133, a cell-surface marker for ventricular zone cells, was expressed specifically in these GFP-positive $\left(\mathrm{GFP}^{+}\right)$ cells. After sorting by fluorescence-activated cell sorting, the $\mathrm{GFP}^{+}$cells proliferated in vitro and expressed precursor cell markers but not neuronal markers. Using clonogenic sphere formation assays, we showed that this sorted population was
\end{abstract}

Parkinson's disease is characterized by the selective degeneration of dopaminergic (DA) neurons in the substantia nigra of the

\footnotetext{
Received Dec. 29, 2000; revised March 6, 2001; accepted March 14, 2001.

This work was supported by grants-in-aid for scientific research and special grants for Strategic Promotion System for Brain Science from the Japanese Ministry of Education, Science, Sports, Culture, and Technology, Core Research for Evolutional Science and Technology of the Japan Science and Technology Corporation, and the Human Frontier Science Program. Work in the Goldman laboratory was supported by National Institutes of Health/National Institute of Neurological Disorders and Stroke and by grants from the National Multiple Sclerosis Society, the Mathers Charitable Foundation, and Project Amyotrophic Lateral Sclerosis. We thank Hiroshi Hatanaka and Ikuko Nagatsu for providing the anti-TH antibody, Wieland B. Huttner for the monoclonal antibody 13A4, and Abdellatif Benraiss, Ayano Kawaguchi, Yoshishiro Koyama, Takaki Miyata, Yohei Morita, Hiromitsu Nakauchi, Neeta Singh Roy, Shin-ichi Sakakibara, Kazuhiro Sakurada, and Takuya Shimazaki for their useful technical advice and discussions.

K.S. and N.N. contributed equally to this work.

Correspondence should be addressed to Dr. Hideyuki Okano, Department of Physiology, Keio University School of Medicine, 35 Shinanomachi, Shinjuku, Tokyo 160-8582, Japan. E-mail: hidokano@sc.itc.keio.ac.jp.

Copyright (c) 2001 Society for Neuroscience 0270-6474/01/213895-09\$15.00/0
}

enriched in multipotent precursor cells that could differentiate into both neurons and glia. Importantly, many neurons generated from nestin-GFP-sorted mesencephalic precursors developed a dopaminergic phenotype in vitro. Finally, nestin-GFP ${ }^{+}$ cells were transplanted into the striatum of a rat model of Parkinson's disease. Bromodeoxyuridine-tyrosine hydroxylase double-labeling revealed that the transplanted cells generated new dopaminergic neurons within the host striatum. The implanted cells were able to restore dopaminergic function in the host striatum, as assessed by a behavioral measure: recovery from amphetamine-induced rotation. Together, these findings indicate that precursor cells harvested from the embryonic ventral mesencephalon can generate dopaminergic neurons able to restore function to the chemically denervated adult striatum.

Key words: Parkinson's disease; green fluorescent protein (GFP); fluorescence-activated cell sorting (FACS); dopaminergic neuron; precursor cells; transplantation midbrain (Nagatsu et al., 1984; Agid et al., 1987; Damier et al., 1999). Grafts of embryonic ventral mesencephalon (VM) can survive and reduce motor symptoms after transplantation into the brains of Parkinson's patients and animal models of Parkinson's disease (Brundin et al., 1988; Sauer and Brundin, 1991; Frodl et al., 1994; Lindvall, 1994; Nakao et al., 1994; Haque et al., 1997; Björklund and Lindvall, 2000). Although transplantation is a promising treatment for Parkinson's disease, its clinical application has been limited to a few cases, because it is very difficult to obtain large numbers of human embryonic mesencephalic tissues. To overcome this problem, various candidate cells have been investigated as possible donor cells for transplantation therapy for Parkinson's disease.

Mesencephalic precursor cells derived from the developing midbrain appear to be a good candidate cell source for dopaminergic precursors. Like ventricular zone (VZ) cells elsewhere throughout the neuraxis, mesencephalic precursor cells can expand, self-renew, and generate neuronal progeny. However, un- 
like neural progenitors derived from the telencephalic VZ, these cells have transcription factors characteristic of their midbrain origin (Smidt et al., 1997; Sakurada et al., 1999) and can respond to regional signals by rapidly differentiating as DA neurons (Ye et al., 1998). Because of these features, these cells should provide an especially appropriate cellular substrate for generating DA neurons in vitro (Ling et al., 1998; Studer et al., 1998; Daadi and Weiss, 1999; Potter et al., 1999). Nonetheless, in previous studies, mesencephalic precursor cells that were transplanted into the adult striatum differentiated into DA neurons to only a limited extent (Svendsen et al., 1996, 1997). Thus, it is unclear whether precursor cells taken from the ventral mesencephalic VZ have any particular bias or predisposition to differentiate into DA neurons. To better characterize the intrinsic biases and phenotypic potential of these cells, we needed to isolate a pure population of $\mathrm{VZ}$ precursor cells from fresh VM tissue.

As a first step toward isolating $\mathrm{VZ}$ precursors from the midbrain, we devised a method for labeling live mesencephalic precursor cells. Our plan was that, once labeled, the cells could be directly isolated and their differentiation could be followed over time, both in vitro and in vivo. For this purpose, we established transgenic lines of both mice and rats carrying green fluorescent protein (GFP) under the control of the neural-specific enhancer for the nestin gene (Zimmerman et al., 1994; Lothian and Lendahl, 1997), thereby tagging live neural precursor cells with a viable, real-time fluorescent reporter. We then used fluorescenceactivated cell sorting (FACS) to identify and isolate these cells from the mesencephalic VZ. Finally, the differentiation of the cells was followed in vitro or the cells were directly implanted into chemically lesioned adult rat striatum in vivo.

We report here that these precursor cells retained the capacity to differentiate appropriately as DA neurons, to restore DA function to chemically deafferented striatum, and to reestablish dopamine-dependent motor behaviors.

\section{MATERIALS AND METHODS}

Transgenic mice and rats. To generate the nestin-GFP transgenic rats, fertilized eggs were microinjected with the previously described transgene (Roy et al., 2000a,b; Kawaguchi et al., 2001). The 2.7 kb SalI fragment of the E/nestin:EGFP plasmid was purified and then injected into the pronucleus of fertilized eggs. Sprague Dawley female rats were crossed to the nestin-GFP males to obtain transgenic rat embryos. The nestin-GFP transgenic mice used in this study were described previously (Yamaguchi et al., 2000). C57BL/6 female mice were crossed to the nestin-GFP male mice to obtain transgenic mouse embryos. Transgenic mice and rats were identified by Southern blot analysis or by PCR using tail DNA and primers specific for the GFP sequence.

Dissociated cell culture. Pregnancies were dated by inspection for the vaginal plug, and the day of the plug was defined as embryonic day 0 (E0). VMs were dissected from mouse (E11.5-E12.5) or rat (E13.5-E14.5) embryos in serum-free medium composed of a 1:1 mixture of DMEM and F-12 (Life Technologies, Gaithersburg, MD) and then digested in $0.25 \%$ trypsin (Life Technologies) at $37^{\circ} \mathrm{C}$ for $5 \mathrm{~min}$. The cells were washed with fresh medium and then were triturated with a fire-polished Pasteur pipette. The cells were plated onto coverslips coated with polyethyleneimine (PEI) and cultured in DMEM-F-12 containing insulin (25 $\mu \mathrm{g} / \mathrm{ml})$, transferin $(100 \mu \mathrm{g} / \mathrm{ml})$, progesterone $(20 \mathrm{nM})$, sodium selenate (30 ng), putrescine $(60 \mu \mathrm{M})$, and 10\% fetal bovine serum (FBS).

Sphere culture. Sorted cells were cultured as described previously (Reynolds and Weiss, 1992). In brief, the cells were washed with DMEM-F-12 and resuspended in DMEM-F-12 containing insulin (25 $\mu \mathrm{g} / \mathrm{ml})$, transferring $(100 \mu \mathrm{g} / \mathrm{ml})$, progesterone $(20 \mathrm{nM})$, sodium selenate (30 ng), putrescine $(60 \mu \mathrm{M})$, and basic FGF (bFGF) $(20 \mathrm{ng} / \mathrm{ml})$. Cells were plated at 5000 cells/200 $\mu \mathrm{l}$ per well in ultra-low attachment 96-well plates (Costar, Cambridge, MA). For the differentiation assay, spheres at 7-8 d in vitro were plated onto PEI-coated coverslips and cultured for another 7-10 d in DMEM-F-12 containing 10\% FBS.
Immunofluorescence analyses for cryosections and cultured cells. Embryos were fixed overnight in $4 \%$ paraformaldehyde in PBS, pH 7.4, at $4^{\circ} \mathrm{C}$, cryoprotected in $30 \%$ sucrose in PBS overnight, embedded in O.C.T. compound (Sakura Finetechinical Co. Ltd., Tokyo, Japan), and frozen in liquid nitrogen. Ten-micrometer-thick cryosections were cut and affixed to 3-aminopropyltriethoxysilane-coated glass slides (Matsunami Glass, Osaka, Japan). Cells attached to PEI-coated coverslips were fixed in 4\% paraformaldehyde in PBS for 10 min at room temperature. Fixed cryosections and cultures were washed three times with PBS and permeabilized and blocked in PBS containing $0.3 \%$ Triton X-100 and 10\% donkey serum for $30 \mathrm{~min}$ at room temperature, followed by an overnight incubation in the same buffer at $4^{\circ} \mathrm{C}$ with one or more of the following antibodies: mouse anti-tyrosine hydroxylase (TH) monoclonal antibody (obtained from Dr. Hiroshi Hatanaka, Osaka University, Osaka, Japan) (Hatanaka and Arimatsu, 1984) diluted 1:500; rabbit anti-TH antibody (obtained from Dr. Ikuko Nagatsu, Fujita Health University, Toyoake, Japan) (Nagatsu et al., 1989) diluted 1:10,000; mouse anti- $\beta$ III-tubulin monoclonal antibody (Sigma, St. Louis, MO) diluted 1:100; rat antiMusashi1 monoclonal antibody (Kaneko et al., 2000) diluted 1:500; mouse anti-Ki67 monoclonal antibody (Novocastra Laboratories, Newcastle upon Tyne, UK) diluted 1:1000; mouse anti-Nestin monoclonal antibody rat 401 (Developmental Studies Hybridoma Bank, University of Iowa, Iowa City, IA) diluted 1:500; rabbit anti-dopamine transporter (DAT) polyclonal antibody (Chemicon, Temecula, CA) diluted at 1:1000; rabbit anti-GFAP polyclonal antibody (Dako, High Wycombe, UK) diluted 1:5; mouse anti-microtubule-associated protein 2 (MAP2) monoclonal antibody (Sigma) diluted at 1:100; and rat anti-Prominin monoclonal antibody 13A4 (obtained from Dr. Wieland B. Huttner, University of Heidelberg, Heidelberg, Germany) (Weigmann et al., 1997) diluted 1:300. After three washes with PBS, the sections or cells were incubated with secondary antibodies conjugated with FITC or Cy3 (Jackson ImmunoResearch, West Grove, PA) diluted 1:1000 in PBS, for $1 \mathrm{hr}$ at room temperature. The cultured cells were also incubated briefly with $10 \mu \mathrm{M}$ Hoechst 33342 (Sigma) to stain the nuclei. After three washes with PBS, the samples were mounted on slides and examined with a Zeiss (Oberkochen, Germany) LSM510 confocal imaging system or Zeiss Axioplan2.

Cell sorting. FACS sorting of GFP-positive $\left(\mathrm{GFP}^{+}\right)$cells was performed essentially as described previously (Wang et al., 1998; Roy et al., 2000a,b; Kawaguchi et al., 2001; Sawamoto et al., 2001a). VMs were dissected from embryos in cold DMEM-F-12 medium and digested in $0.25 \%$ trypsin (Life Technologies) at $37^{\circ} \mathrm{C}$ for $5 \mathrm{~min}$. The cells were washed with fresh medium and then were triturated with a fire-polished Pasteur pipette. Dissociated cells were spun, resuspended in PBS containing $10 \mu \mathrm{g} / \mathrm{ml}$ propidium iodide (PI) and $0.05 \%$ sodium azide, and filtered through nylon mesh. Sorting and analyses of fluorescent cells were performed on an FACS Vantage flow cytometer/cell sorter (Becton Dickinson, Franklin Lakes, NJ). Data analyses were performed using CELLQuest software (Becton Dickinson). Cells $\left(1-2 \times 10^{-6} / \mathrm{ml}\right)$ were analyzed for forward scatter, side scatter, PI fluorescence, and GFP fluorescence with an argon laser $(488 \mathrm{~nm}, 100 \mathrm{~mW})$. Dead cells were excluded by gating on forward and side scatter and by eliminating PI-positive events. Cells harvested from wild-type mice were used to set the background fluorescence. Viable and fluorescent cells from the transgenic embryos were sorted into DMEM-F-12 medium at a speed of 3000 cells per second. For anti-Prominin staining, the VM cell suspension was incubated with the monoclonal antibody $13 \mathrm{~A} 4$ for $30 \mathrm{~min}$ on ice. The cells were washed with PBS and then stained with phycoerythrin (PE)-conjugated anti-rat IgG, followed by washing. The stained cells were resuspended in PBS containing $10 \mu \mathrm{g} / \mathrm{ml}$ PI and $0.05 \%$ sodium azide and applied to the flow cytometer for analysis.

Unilateral 6-hydroxydopamine lesions and amphetamine-induced circling behavior. Young adult male Sprague Dawley rats (Charles River, Osaka, Japan), weighing 180-200 gm at the start of the experiment were used. The rats were maintained under a $12 \mathrm{hr}$ dark/light cycle with ad libitum access to food and water. All surgical procedures were conducted under anesthesia with sodium pentobarbital $(50 \mathrm{mg} / \mathrm{kg}$, i.p.). Unilateral lesions of the ascending mesostriatal DA pathway were made by intracerebral injections of 6-hydroxydopamine (6-OHDA) $(3 \mathrm{mg} / \mathrm{ml}$ in $0.2 \mathrm{mg} / \mathrm{ml}$ ascorbate-saline; Sigma), as described in detail previously (Nakao et al., 1998). Two weeks after the lesion surgery, amphetamine $(0.25 \mathrm{mg} / \mathrm{kg}$, i.p.)-induced turning behavior was monitored over a period of $60 \mathrm{~min}$. The rats that exhibited a net rotational asymmetry of at least six full turns per minute toward the lesioned side were selected for transplantation surgery, because this extent of amphetamine-induced rotational 
asymmetry corresponds, on average, to a $99 \%$ depletion of striatal DA neurons (Schmidt et al., 1983). The drug-induced rotational behavior was tested again 5 weeks after grafting to examine the functional effects of the implanted $\mathrm{GFP}^{+}$cells.

Transplantation surgery. The sorted $\mathrm{GFP}^{+}$cells were spun and resuspended in a final volume of 100-150 $\mu \mathrm{l}$ of HBSS. The cell viability, assessed with a trypan blue dye exclusion test, was over $95 \%$ just before grafting, and the cell concentration was $10,000-13,000$ per microliter Lesioned rats were divided into two groups: lesion control $(n=4)$ and transplantation $(n=5)$. In the transplantation group, two stereotaxic deposits, of $2 \mu \mathrm{l}$ of cell suspension each, were injected into the lesioned striatum as described previously (Nakao et al., 1994, 1998). All of the engrafted rats were given intraperitoneal injections of bromodeoxyuridine (BrdU) (50 mg/kg; Sigma) for 14 consecutive days, starting on the day of transplantation surgery.

Tissue processing. The animals were anesthetized with lethal doses of sodium pentobarbital and perfused transcardially with physiological saline, followed by $4 \%$ paraformaldehyde in $0.1 \mathrm{M}$ phosphate buffer, $\mathrm{pH}$ 7.4. After a $6 \mathrm{hr}$ post-fixation incubation in the same fixative, the brains were immersed in $20 \%$ sucrose in $0.1 \mathrm{M}$ phosphate buffer at $4^{\circ} \mathrm{C}$ until they sank. Sections were cut at $30 \mu \mathrm{m}$ in a cryostat and collected in PBS.

For quantification of the number of grafted cells expressing the DA phenotype, free-floating sections were processed for $\mathrm{TH}$ immunohistochemistry as described previously (Nakao et al., 1994, 1998). Briefly, the sections were preincubated in $10 \%$ blocking serum $-0.2 \%$ Triton $\mathrm{X}-100-$ PBS for $1 \mathrm{hr}$ at room temperature and then incubated overnight at room temperature with primary antibodies against tyrosine hydroxylase (1:500; Pel-Freeze). Subsequently, the tissue was exposed to biotinylated antirabbit IgG (1:200; Vector Laboratories, Burlingame, CA) for $1 \mathrm{hr}$ at room temperature. The bound antibodies were visualized using an avidin-biotin-peroxidase complex system (Vectastain ABC Elite kit; Vector Laboratories), with 3,3-diaminobenzidine as the chromogen. The number of TH-immunoreactive neurons in each graft was counted under bright-field illumination on every third section. The raw counts of THimmunoreactive cells were corrected according to the formula of Abercrombie (1946).

Some brain sections were also processed for immunofluorescence double-labeling to determine whether new DA neurons might be generated from grafted $\mathrm{GFP}^{+}$cells by mitotic neurogenesis. Free-floating sections were pretreated in $50 \%$ formamide $-2 \times \mathrm{SSC}$ at $65^{\circ} \mathrm{C}$ for $2 \mathrm{hr}$, incubated in $2 \mathrm{~N} \mathrm{HCl}$ at $37^{\circ} \mathrm{C}$ for $30 \mathrm{~min}$, and then rinsed for $10 \mathrm{~min}$ in $0.1 \mathrm{M}$ boric acid, $\mathrm{pH}$ 8.5. Brain sections were incubated overnight with mouse monoclonal anti-BrdU (1:100; NeoMarkers, Fremont CA) and for $2 \mathrm{hr}$ with biotinylated horse anti-mouse antibody (1: 200; Vector Laboratories). Sections were then incubated with ExtraAvidin-FITC conjugate $(10 \mathrm{mg} / \mathrm{ml}$; Sigma) for $2 \mathrm{hr}$. After three $5 \mathrm{~min}$ washes with PBS, the sections were incubated overnight with anti-TH antibody (1:500; PelFreeze), followed by a $2 \mathrm{hr}$ incubation with Cy3-labeled sheep anti-rabbit IgG (1:50; Chemicon). Sections were thoroughly washed in PBS and then mounted on glass slides and covered with coverslips. Fluorescent signals were detected and processed using a confocal scanning laser microscope (Olympus Optical, Osaka, Japan).

Statistical analyses. All data were expressed as the mean \pm SEM. A paired two-tailed Student's $t$ test was used to compare amphetamineinduced rotation scores before and after grafting. $p<0.05$ was considered significant.

\section{RESULTS}

\section{Specific expression of the nestin-GFP transgene in the ventricular zone of the ventral mesencephalon}

To label live precursor cells in the ventral mesencephalon, we used a GFP reporter gene placed under control of the regulatory elements of the nestin gene (Roy et al., 2000a,b; Yamaguchi et al., 2000; Kawaguchi et al., 2001; Sawamoto et al., 2001). We first examined the expression pattern of GFP in the VM of NestinGFP mouse embryos at E11.5. At this stage, DA neurons are generated in the ventricular zone of the VM by mitotic neurogenesis (Kawano et al., 1995). Under a fluorescence stereomicroscope, GFP fluorescence was detected throughout the developing CNS, including the mesencephalon (Fig. $1 A, B$ ). To determine where GFP was expressed within the VM, coronal sections through the mesencephalon were examined. nestin-driven GFP
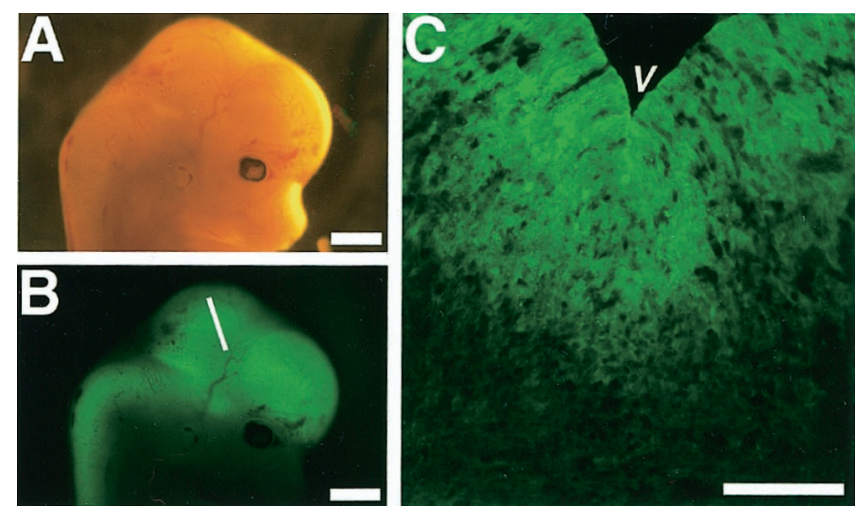

Figure 1. Mesencephalon of a nestin-GFP embryo. $A, B$, Head of an E12.5 nestin-GFP embryo. $A$, Bright-field image. $B$, GFP fluorescence was detected throughout the CNS. $C$, A coronal section of the ventral mesencephalon (indicated by white line in $B$ ). GFP fluorescence was detected in the ventricular zone. Scale bars: $A, B, 1 \mathrm{~mm} C, 100 \mu \mathrm{m}$.

fluorescence was brightest in ventricular zone cells in the VM and very weak outside of the $\mathrm{VZ}$ (Fig. 1C), which is an expression pattern similar to that of the Nestin protein and mRNA (Hockfield and McKay, 1985; Dahlstrand et al., 1995).

Sections of mesencephalon dissected from E11.5 nestin-GFP mouse embryos were then fixed and immunostained with antibodies against cell type-specific markers in combination with Cy3-conjugated secondary antibodies (Fig. 2). Figure 2A-C shows a section stained with anti-TH antibody. In the VM, TH is expressed only in the DA neurons (Kalsbeek et al., 1992). The $\mathrm{TH}^{+}$DA neurons were not located in the $\mathrm{GFP}^{+}$ventricular zone. We next stained sections with an antibody against $\beta$ IIItubulin, a marker for postmitotic neurons (Fig. $2 D-F$ ). The pattern of GFP expression was essentially reciprocal to that of $\beta$ III-tubulin (Fig. $2 D-F$ ), suggesting that the nestin-GFP transgene was expressed by neural precursor cells in the VZ at a high level but was downregulated rapidly during neuronal differentiation. On the other hand, the expression pattern of GFP overlapped with the immunoreactivity of Musashi1 (Fig. 2G-I), an RNA-binding protein that is highly enriched in CNS precursor cells (Sakakibara et al., 1996; Kaneko et al., 2000). We also examined whether GFP was expressed in mitotic cells. To label the nuclei of actively dividing cells in the VZ, we stained sections with an antibody against the Ki67 antigen, which is expressed specifically in proliferating cells (Gerdes et al., 1983). We found that a population of $\mathrm{Ki}^{+} 7^{+}$cells in the VZ expressed GFP (Fig. $2 J-L)$. These results imply that the nestin-GFP is active in precursor cells in the VZ, including mitotic neural progenitor cells, but is downregulated during differentiation and departure from the VZ.

To more precisely define the antigenic phenotype of the $\mathrm{GFP}^{+}$ cells, dissociated VM cells derived from nestin-GFP embryos were cultured for $24 \mathrm{hr}$ and then fixed and immunostained for cell type-specific markers. All $\mathrm{GFP}^{+}$cells were immunoreactive to anti-Nestin (Fig. 2M-O) and to anti-Musashi1 (data not shown). In contrast, the $\mathrm{GFP}^{+}$cells were negative for TH (Fig. $2 P-R$ ). The $\mathrm{GFP}^{+}$cells were also negative for neuronal $(\beta$ III-tubulin and MAP2) and astrocytic (GFAP) markers (data not shown).

Together, these results suggest that, in the VM, nestindriven GFP expression was more robust in undifferentiated progenitor cells than in their differentiated daughters, including $\mathrm{TH}^{+}$DA neurons. 

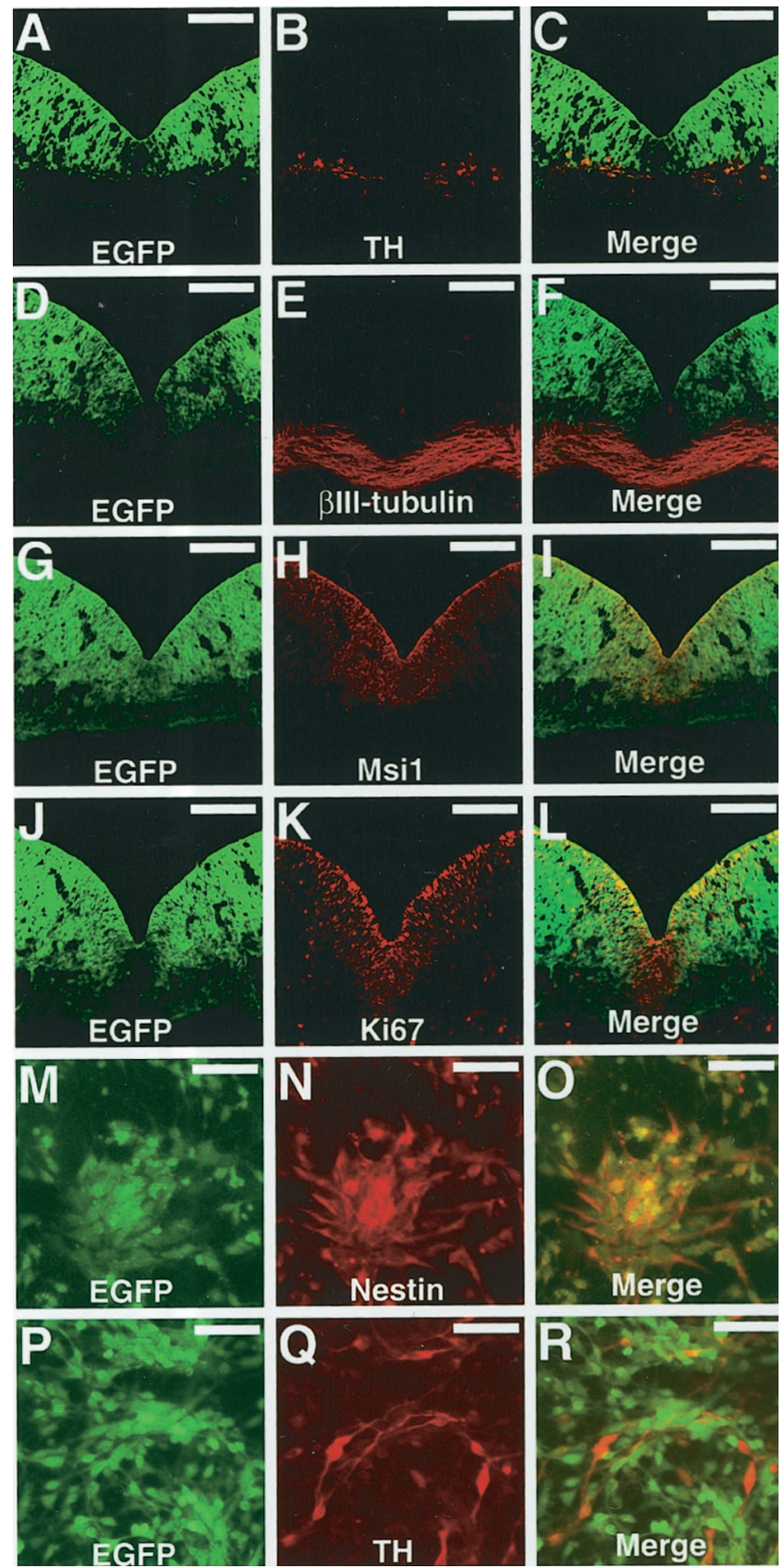

Figure 2. Expression pattern of the nestin-GFP transgene in the ventral mesencephalon. $A-L$, Coronal sections of the ventral mesencephalon from nestin-GFP E11.5 embryos were stained with antibodies against tyrosine hydroxylase $(A-C)$, $\beta$ III-tubulin $(D-F)$, Musashi1 $(G-I)$, or $\mathrm{Ki67}(J-L) . M-R$, Dissociated cells from the nestin-GFP ventral mesencephalon were stained with antibodies against Nestin $(M-O)$ or tyrosine hydroxylase $(P-R)$. Each antibody was visualized with a $\mathrm{Cy} 3$-conjugated secondary antibody (red). Scale bars: $A-L, 100 \mu \mathrm{m} ; M-R, 25 \mu \mathrm{m}$.

\section{Direct isolation of VM precursor cells by FACS}

The expression patterns of nestin-GFP in the embryo (Figs. 1, 2) raised the possibility that we could use flow cytometry to identify and isolate neural precursor cells in the VZ as a cell population expressing GFP. We first analyzed the GFP fluorescence intensity of dissociated VM cells from E11.5-E12.5 embryos. More than $80 \%$ of the total cells from nestin-GFP embryos showed a brighter green fluorescence than did any of the control cells, which were
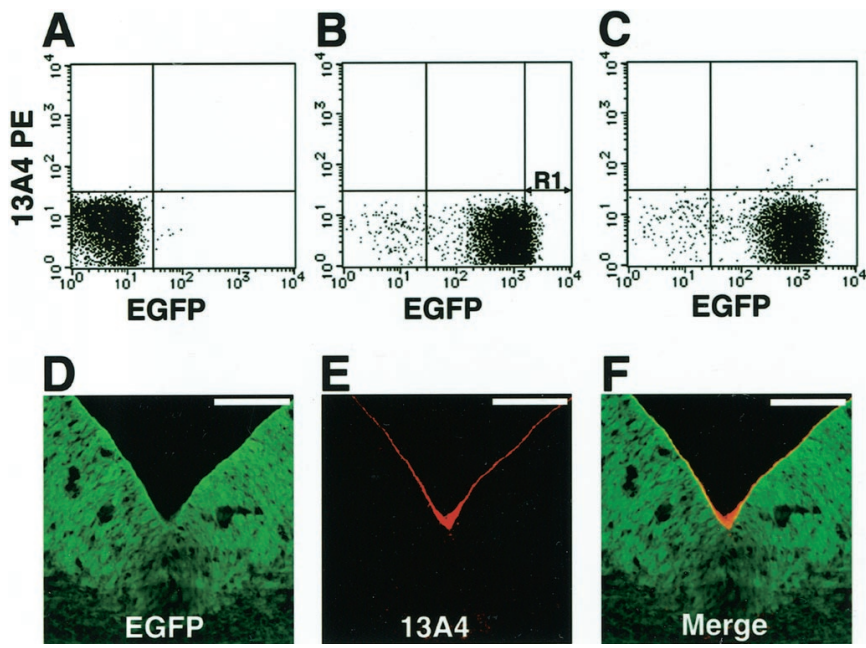

Figure 3. Isolation of nestin- $G F P^{+}$cells from the embryonic VM. $A-C$, Flow-cytometric analyses of mesencephalic cells. $A$, VM cells from wildtype embryos were incubated with PE-conjugated anti-rat IgGs. $B, \mathrm{VM}$ cells from nestin-GFP embryos were incubated with PE-conjugated antirat IgG. $C, \mathrm{VM}$ cells from nestin-GFP embryos were incubated with rat monoclonal antibody 13A4 (anti-Prominin) and PE-conjugated anti-rat IgG. $D-F$, A coronal section of E11.5 nestin-GFP ventral mesencephalon stained with anti-Prominin and a $\mathrm{Cy} 3$-conjugated secondary antibody (red). Scale bars, $100 \mu \mathrm{m}$.

derived from the VMs of age- and strain-matched nontransgenic mice (Fig. $3 A, B$ ). This was consistent with our observation that most of the cells outside of the VZ also had very weak but detectable green fluorescence (for example, see Fig. 1C).

To confirm that the $\mathrm{GFP}^{+} \mathrm{VM}$ cell population isolated by flow cytometry contained cells from the ventricular zone, we labeled cells with the monoclonal antibody $13 \mathrm{~A} 4$, which recognizes the extracellular portion of Prominin, a plasma membrane protein specifically expressed on the apical surface of epithelial cells (Weigmann et al., 1997). To examine the localization of Prominin in the VM, coronal sections of the mesencephalons from nestinGFP mice were stained with $13 \mathrm{~A} 4$, followed by a Cy3-conjugated secondary antibody (Fig. 3D-F). Prominin expression was detected only on the apical surface of the ventricle, in which nestindriven GFP was brightest.

We then stained a VM cell suspension from nestin-GFP VM tissue with $13 \mathrm{~A} 4$ and a PE-conjugated secondary antibody and analyzed this binding simultaneously with GFP fluorescence (Fig. $3 C$ ). Almost all of the 13A4-positive cells showed bright GFP fluorescence, which was consistent with our observation that GFP fluorescence was brightest near the ventricular wall (Figs. $1 C$, $2 A-L$ ), in which mitotic neurogenesis occurs. [We reported previously that the intensity of nestin-driven GFP expression in neural cells correlated with their mitotic and neurogenic potentials (Kawaguchi et al., 2001).]

Therefore, to obtain a highly purified population of precursor cells, the $10-15 \%$ of the total cell population (Fig. $3 B, R 1$ ) that had the brightest relative fluorescence was sorted as $\mathrm{GFP}^{+}$cells and used for the analyses described below. Reanalysis of the sorted $\mathrm{GFP}^{+}$cell population by flow cytometry confirmed that all of the sorted cells expressed GFP (data not shown). The sorted $\mathrm{GFP}^{+}$cells were allowed to attach to coverslips and stained with antibodies against Nestin, $\beta$ III-tubulin, and TH. As expected, virtually all of the $\mathrm{GFP}^{+}$cells were positive for Nestin and negative for $\beta$ III-tubulin and TH (data not shown), suggesting that we had isolated a nearly pure population of precursor cells. 


\section{In vitro characterization of the sorted $\mathrm{GFP}^{+}$cells}

Because the anti-Ki67 staining of sections indicated that a subpopulation of the $\mathrm{GFP}^{+}$cells was actively dividing in vivo (Fig. $2 J-L)$, we next examined whether the isolated $\mathrm{GFP}^{+}$cells could also proliferate in vitro. Sorted cells were plated onto PEI-coated coverslips and cultured in DMEM-F-12-based serum-free media with epidermal growth factor (EGF) and bFGF (20 ng/ml each). Cells were treated for $1 \mathrm{hr}$ with $\operatorname{BrdU}(10 \mu \mathrm{M}) 1.5 \mathrm{hr}$ after plating, fixed, and stained with anti-BrdU. Of the total cells counted $(n=$ 2152), 7.8\% (168 cells) had BrdU-labeled nuclei. In contrast, the sorted GFP-negative $\left(\mathrm{GFP}^{-}\right)$population incorporated BrdU into only $2 \%$ (27 cells) of the total cells $(n=1313)$. These results indicate that, under these culture conditions, fetal brain cells with bright GFP fluorescence were mitotic compared with those in which nestin transcription was no longer active.

We next examined whether the $\mathrm{GFP}^{+} \mathrm{VM}$ cell population contained neural stem cells that were multipotent and had the capacity to self-renew. To evaluate these characteristics, we used a culture system in which neural stem cells selectively proliferate to form multicellular aggregates called neurospheres (Reynolds and Weiss, 1992). For this procedure, the sorted cells were counted and plated at a density of 5000 cells per well (Fig. 4A). The cells were then cultured in serum-free medium supplemented with $20 \mathrm{ng} / \mathrm{ml}$ bFGF. We observed a number of small growing neurospheres that were composed of fluorescent cells as early as $2 \mathrm{~d}$ after plating (Fig. 4B). Seven days after plating, we counted the number of fluorescent neurospheres whose diameter was $>50$ $\mu \mathrm{m}$ (Fig. 4C). We found a striking difference between the potential of $\mathrm{GFP}^{+}$cells and $\mathrm{GFP}^{-}$cells (cells without fluorescence or with a lower intensity of fluorescence than the $\mathrm{GFP}^{+}$cells) to generate spheres. $\mathrm{GFP}^{+}$cells generated $33 \pm 8.6$ spheres per well $(n=8)$, whereas $\mathrm{GFP}^{-}$cells generated only $2 \pm 0.9$ spheres per well $(n=8)$. In addition, the size of the spheres derived from the $\mathrm{GFP}^{+}$cells was greater than that of the spheres from $\mathrm{GFP}^{-}$cells; $\mathrm{GFP}^{+}$cells generated $9.2 \pm 3.0$ spheres with a diameter of $>100$ $\mu \mathrm{m}$ per well $(n=7)$, but no spheres of this size could be found in the $\mathrm{GFP}^{-}$cultures $(n=7)$.

We next examined the lineage potential of the sphere-initiating cells that were enriched in the $\mathrm{GFP}^{+}$fraction. For this purpose, we transferred spheres formed in $\mathrm{GFP}^{+}$cultures to PEI-coated coverslips and cultured them in medium containing FBS. After 16 $\mathrm{hr}$, the spheres had flattened but incompletely; cells in the edge region of the colony spread well, but those in the center still formed multicellular aggregates (Fig. 4D). We then examined the GFP expression in the colonies using fluorescence microscopy. The cells in the aggregate at the center of the colony showed green fluorescence, but the spreading cells at the edge did not (Fig. 4E). The colonies were then cultured as monolayers for $14 \mathrm{~d}$, after which the cell sheets were stained with antibodies against neuronal (MAP2 and $\beta$ III-tubulin), astrocytic (GFAP), and oligodendrocytic $(\mathrm{O} 4)$ markers. All of the colonies examined $(n=$ 20) contained these three cell types (data not shown), indicating that the $\mathrm{GFP}^{+}$cells that gave rise to the colonies were multipotent. Putative DA neurons that were positive for TH and/or DAT, as well as MAP2, were also observed in most of the colonies (Fig. $4 F-Q)$. In parallel with these experiments, we also sorted $\mathrm{GFP}^{+}$ cells from the striatum. The striatum-derived $\mathrm{GFP}^{+}$cells generated neurospheres as described previously (Kawaguchi et al., 2001); however, they never differentiated into neurons that were positive for TH or DAT (data not shown).

Finally, to examine the capacity of the sorted $\mathrm{GFP}^{+}$cells for
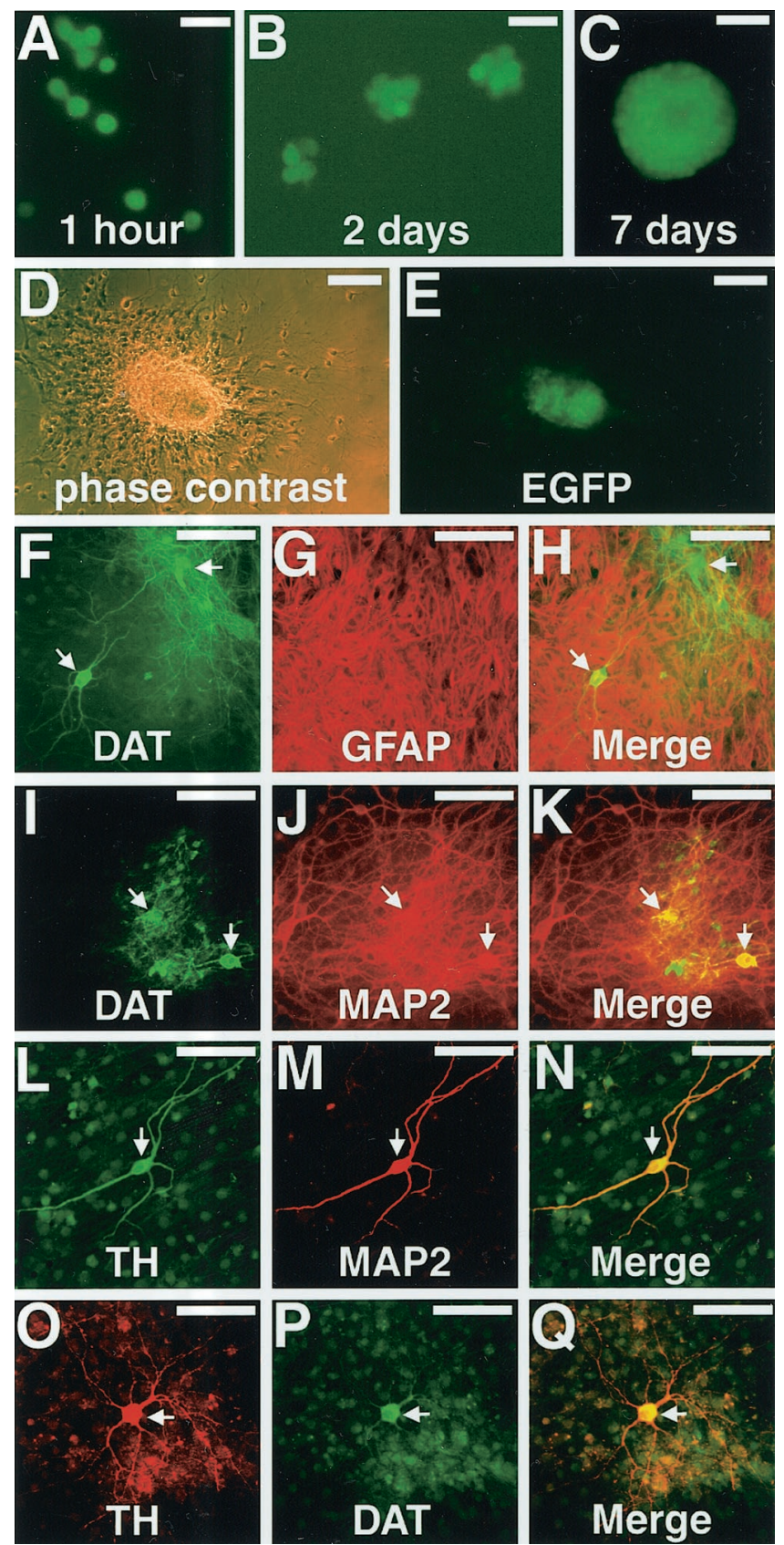

Figure 4. The sorted nestin-GFP ${ }^{+}$cells generated neurospheres. $A-D$, GFP fluorescent images of growing spheres at days $0(A), 2(B)$, and 7 (C). $D-E$, Cell sheet derived from a single neurosphere $16 \mathrm{hr}$ after transferring it onto an adhesive coverslip. $D$, Phase contrast. E, GFP fluorescence was detectable only in the center of the colony in which cells still existed as multicellular aggregates. $F-Q$, Cell sheets after $10 \mathrm{~d}$ of differentiation stained with antibodies against DAT and GFAP $(F-H)$, DAT and MAP2 $(I-K)$, TH and MAP2 $(L-N)$, or TH and DAT $(O-Q)$. Putative DA neurons are indicated by arrows. Scale bars: $A, B, 15 \mu \mathrm{m}$; $C-E, 50 \mu \mathrm{m} ; F-Q, 25 \mu \mathrm{m}$.

self-renewal, primary spheres were individually transferred to separate wells and then dissociated into single cells. These single sphere-derived cells were then cultured and assessed for secondary sphere formation. After $7 \mathrm{~d}, 50 \pm 19$ spheres per well $(n=7)$ showing GFP fluorescence similar to the primary spheres were generated. These results further indicated that the sphereinitiating cells sorted as $\mathrm{GFP}^{+}$cells were both self-renewing and multipotent. 

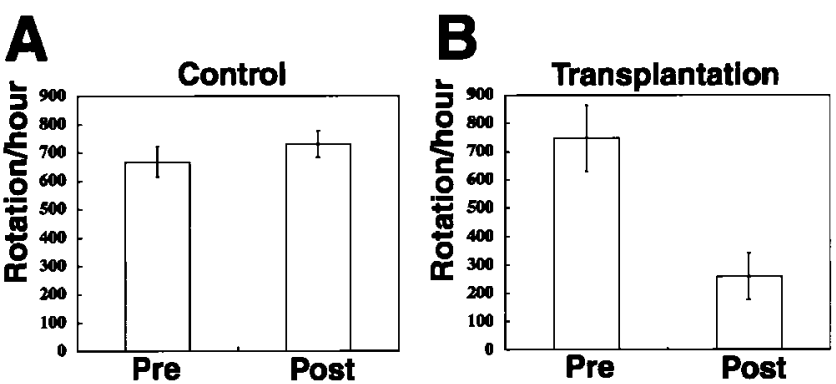

Figure 5. Transplanted $\mathrm{GFP}^{+}$cells caused functional recovery in a rat model of Parkinson's disease. $A, B$, Net ipsilateral amphetamine induced rotation asymmetry over the $60 \mathrm{~min}$ test session. $A$, Control animals $(n=$ 4) showed no improvement. $B$, The animals with grafts $(n=5)$ showed steady improvement.

\section{Transplantation of the sorted $\mathrm{GFP}^{+}$cells into a rat model of Parkinson's disease}

To study the function of the sorted $\mathrm{GFP}^{+}$cells in vivo, we used a rat model of Parkinson's disease (for review, see Brundin et al., 1994). To obtain donor cells that could be transplanted into rats without immunosuppression, we generated transgenic rats carrying a nestin-GFP transgene. The expression pattern of GFP in the ventricular zone and the nature of the sorted $\mathrm{GFP}^{+}$cells in vitro were similar to those seen in mice. GFP expression in the ventricular zone was restricted to cells that were positive for Musashi1 and Nestin but negative for TH and $\beta$ III-tubulin (data not shown), and $\mathrm{GFP}^{+}$cells sorted from the VM of nestin-GFP rat embryos at E13.5-E14.5 (which corresponds to E11.5-E12.5 in mice) contained virtually no $\mathrm{TH}^{+}$neurons. Furthermore, pilot transplantation experiments using mouse cells as donors gave data similar to those using rat cells (data not shown). Therefore, we show here only the results from experiments using the rat cells as donors.

The chosen rat model permits a behavioral assessment (rotation response to amphetamine) of the extent to which the Parkinson's symptoms have been alleviated (Schmidt et al., 1983). In this experiment, all of the animals with a unilateral 6-OHDA lesion displayed a robust rotation response to amphetamine before transplantation, and there was no significant difference in rotation scores between the rats assigned to the lesion control and transplantation groups ( $p>0.05$; unpaired two-tailed Student $t$ test). In the transplantation group, each rat received a total of $\sim 50,000$ grafted cells in the lesioned striatum. Five weeks after grafting the cells, a significant reduction in rotational asymmetry was observed in the grafted rats $(p<0.01)$ (Fig. $5 B)$, whereas the lesion control animals did not show any improvement $(p>0.05)$ (Fig. 5A). The rotation scores of the grafted animals were reduced $65.2 \%$ on average compared with the pretransplantation scores.

The 6-OHDA lesions of the mesostriatal bundle produced a virtually complete loss of $\mathrm{TH}^{+}$DA neurons in the substantia nigra with a concomitant depletion of $\mathrm{TH}$-immunoreactive fibers in the lesioned striatum. During examination of the brain tissues, each rat that had received $\mathrm{GFP}^{+}$cells was found to have two grafts containing $\mathrm{TH}^{+}$cells in the rostral part of the host striatum. Individual $\mathrm{TH}^{+}$cells within the grafts displayed morphological features suggestive of mature neurons and extended numerous $\mathrm{TH}^{+}$fibers into the DA-depleted striatum (Fig. 6A). Each rat had a mean number of $624 \pm 123 \mathrm{TH}^{+}$cells in the two graft deposits. The percent reduction in net rotational asymmetry
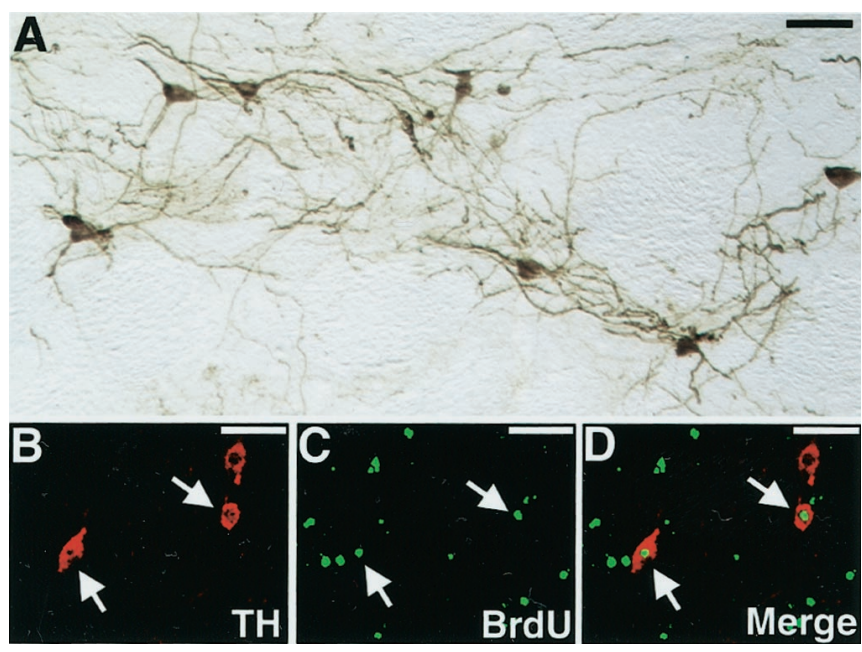

Figure 6. Morphology of $\mathrm{TH}^{+}$neurons in the graft. $A$, Brain sections of the 6-OHDA-lesioned animals that received sorted $\mathrm{GFP}^{+}$cells were immunostained for TH. $B-D$, Evidence that transplanted $\mathrm{GFP}^{+}$cells generated new $\mathrm{TH}^{+}$neurons. $B$, Anti-TH staining (red). $C$, Anti-BrdU staining (green). $D$, Merged image. Scale bars, $100 \mu \mathrm{m}$.

of individual animals was plotted against the number of surviving $\mathrm{TH}^{+}$neurons, and linear regression analysis was performed. These two parameters were found to be significantly correlated $\left(p<0.005 ; r^{2}=0.851\right)$.

To label the new DA neurons generated from the donor cells by mitotic neurogenesis, the host animals were injected with BrdU daily for 2 weeks. The sections through the graft were stained with anti-BrdU and anti-TH antibodies (Fig. $6 B-D$ ). The rats contained an average of $47.2 \pm 12.0$ cells $(n=5)$ that were positive for both BrdU and $\mathrm{TH}$ in the striatum. Nuclei in $7.2 \pm$ $0.8 \%$ of the $\mathrm{TH}^{+}$cells $(n=5)$ were labeled with BrdU. Thus, enough transplanted precursor cells differentiated into functional DA neurons to improve the amphetamine-induced rotational asymmetry in this rat model of Parkinson's disease.

\section{DISCUSSION}

Midbrain DA neurons are generated from precursor cells in the ventricular zone of the developing VM. After mitosis in the ventricular zone, the precursor cells migrate radially, start to express specific markers including $\mathrm{TH}$, and differentiate into mature DA neurons (Kawano et al., 1995). Because of the DA character of these cells, they are an interesting candidate source for donor cells that could be used in transplantation therapy for Parkinson's disease. Most studies of these precursor cells have been based on cells acquired by expanding dissociated cell cultures. However, after long-term culture under mitogenic stimulation, these expanded cell populations may become chromosomally abnormal and phenotypically unrepresentative of their founder populations. Therefore, large-scale expansion from a small number of progenitors may not be the best strategy for studying their native potential. The selection of mesencephalic precursor cells based on surface markers, a common and effective strategy in the hematopoetic system, is hampered in the neural system by the lack of surface antigens specific for the neural precursor phenotype. As an alternative strategy, we have developed a technique to visualize and isolate a specific cell type by labeling neural cells with GFP under the control of a specific promoter (for review, see Okano and Goldman, 2000). Using a nestin-GFP transgene, we demonstrated a strong correlation be- 
tween GFP expression and the immature precursor cell phenotype in the forebrain (Kawaguchi et al., 2001). Here, we used the nestin-GFP transgene to visualize and identify mesencephalic precursor cells in the ventricular zone. As expected, GFP fluorescence was restricted to cells within the ventricular zone expressing Musashi1 and Nestin. Expression of GFP was near the background level in the postmitotic neurons that were positive for $\beta$ III-tubulin and/or TH. Almost all of the mitotic cells $\left(\mathrm{Ki}_{67}{ }^{+}\right)$ expressed bright GFP fluorescence in the ventricular zone. Thus, we established that nestin-GFP was a useful and reliable marker for mesencephalic precursor cells.

To confirm that we could identify the precursor cells by flow cytometry as a population of cells with a bright GFP fluorescence, we used an antibody against Prominin. Prominin is a transmembrane protein that is expressed in the microvilli of the apical surface of epithelial cells, including those of the neuroepithelium (Weigmann et al., 1997). Recently, an antibody against the human homolog of Prominin, CD133, was used to enrich for human neural stem cells that initiate neurosphere generation (Uchida et al., 2000). Here, we found that Prominin was expressed on the ventricular surface in the developing mouse mesencephalon, indicating that Prominin could be used as a surface marker for neural precursor cells in mice. In flow cytometry, Prominin immunoreactivity was detected specifically on the cells that expressed the nestin-GFP transgene. The expression pattern of nestin-GFP using frozen sections, cultured cells, and cell suspensions suggested that the sorted nestin-GFP ${ }^{+} \mathrm{VM}$ cells constituted a nearly pure population of precursor cells.

In vitro analysis indicated other characteristics that identified the sorted cell population as precursor cells. First, almost all of the sorted cells were positive for Nestin and Musashi1 but not for TH. Second, the sorting based on nestin-GFP fluorescence resulted in an enrichment of mitotically active cells in vitro. Third, this population included neural stem cells that could generate neurospheres. Finally, each sphere differentiated into multiple types of cells, including neurons that expressed DA markers such as TH and DAT (Lorang et al., 1994). It is known that virtually all spheres are clonally derived when cells are plated at a density $<5 \times 10^{-4}$ cells/ml (Hulpas et al., 1997). Therefore, these results imply that the nestin-GFP ${ }^{+}$population contained multipotential precursor cells that could generate DA neurons. Thus, sorting nestin- $\mathrm{FFP}^{+}$cells enabled us to obtain a nearly pure population of live VM precursor cells for the first time. The sorted cells should be a useful source of material for biological analyses of DA neurons and clinical studies for neurological disorders caused by defects in DA neurons.

Embryonic VM tissue used for transplantation contains a mixture of at least (1) differentiated neurons that have already undergone final mitosis, (2) immature neurons that have also undergone final mitosis but not started to express neuronal markers, and (3) neural progenitor cells that are still mitotic. However, it was unclear whether all of these cells have the potential to develop into functional DA neurons after transplantation. A recent study found that the great majority of $\mathrm{TH}^{+}$neurons in nigral grafts were derived from postmitotic DA neurons that were already present in the VM tissue at the time of implantation (Sinclair et al., 1999). We also demonstrated that purified DA neurons could survive transplantation and improve Parkinson's disease (Sawamoto et al., 2001b). However, the potential of precursor cells to generate DA neurons in the adult brain was not studied sufficiently. Here, for the first time, we could evaluate the function of mesencephalic precursor cells isolated directly from the mixed population of cells in VM tissue. We transplanted $\sim 50,000$ precursor cells in the striatum, and found that $1.25 \%$ of them $(624 \pm 123$ cells $)$ survived as $\mathrm{TH}^{+}$neurons at the end of the experiments. Because the sorted $\mathrm{GFP}^{+}$population did not contain any $\mathrm{TH}^{+}$cells, we could ascertain that the $\mathrm{TH}^{+}$cells detected in the grafts were generated after transplantation into the host brain.

The sorted cell population should include both mitotic and postmitotic precursors. Importantly, we obtained clear evidence that a subpopulation of the sorted precursor cells could generate new DA neurons by mitotic neurogenesis in the adult striatum, by BrdU labeling studies. Seven percent of the $\mathrm{TH}^{+}$neurons in the grafts contained BrdU in their nuclei. Because the protocol for BrdU injection (once per day) used in this study probably did not label all of the DA neurons generated after transplantation, these data $(7 \%)$ might underestimate the amount of mitosis that occurred in the host striatum. Thus, the present results indicate that primary precursor cells that have been isolated directly from fresh VM tissue possess a high potential to generate new DA neurons in the adult striatum. Furthermore, others have demonstrated recently that the adult striatum lesioned with 6-OHDA may provide a supportive environment for the differentiation of DA neurons (Zigova et al., 1998; Nishino et al., 2000).

The $\mathrm{TH}^{+} \mathrm{BrdU}^{-}$neurons in the grafts were likely to be implanted as immature postmitotic cells that began to express $\mathrm{TH}$ in the host striatum. There may be advantages to implanting postmitotic immature, rather than mature, DA neurons. For example, the dissociation of mature DA neurons in brain tissue is likely to cause serious damage to cells from the disruption of axons and dendrites. Because immature cells have a simple morphology, the dissociation process may not affect their viability and ability to innervate tissue after implantation. In addition, postmitotic cells should have already committed to a cell fate in the developing VM. Therefore, they ought to be able to develop into mature DA neurons even if they are transplanted into an ectopic environment. In fact, in this study, the $\mathrm{TH}^{+}$neurons found in the grafts had long axons innervating the host tissue, a morphological feature they share with endogenous DA neurons.

The physiological function of the DA neurons generated from the sorted cell population was analyzed based on recovery from the amphetamine-induced rotation behavior in a rat model of Parkinson's disease. All of the animals that received the sorted precursors in their striatum showed significant recovery in the amphetamine-induced rotation behavior. We found a good correlation between the DA neuron cell number in the grafts and the degree of recovery, suggesting that dopamine secretion from the generated DA neurons was responsible for the improvement of the phenotype. Taking together the data on behavioral recovery and the successful transplantation of DA neurons, we conclude that the sorted precursors generated functional DA neurons in vivo that could survive and innervate the adult striatum.

In contrast with our results, the transplantation of mesencephalic precursors that had been expanded in vitro as neurospheres did not result in sufficient differentiation into DA neurons to completely resolve the behavioral defects seen in the same rat model of Parkinson's disease (Svendsen et al., 1996, 1997). Although it is unknown why in vitro expansion of precursor cells might result in a loss of their potential to differentiate into DA neurons, it is possible that, under the conditions used for expansion, the cells were altered and lost their identity as DA precursors. Endogenous precursor cells have access to positional information that is important for adopting a specific fate. Long-term 
culture under stimulation with growth factors causes the loss of such positional information for unknown reasons (Santa-Olalla et al., 2000). For the application of precursor cells to transplantation therapy of Parkinson's disease, it is necessary to establish culture conditions that maintain their potential for DA differentiation, as well as their viability (Brundin and Björklund, 1998) after expansion in vitro. This work should stimulate future research aimed at the characterization of the VM precursor cells, as well as the molecular mechanisms by which precursor cells generate DA neurons.

\section{REFERENCES}

Abercrombie M (1946) Estimation of nuclear population from microtome sections. Anat Rec 94:239-247.

Agid Y, Javoy-Agid F, Ruberg M (1987) Biochemistry of neurotransmitter in Parkinson's disease. In: Movement disorder, Vol 2 (Marsden CD, Fahn S, eds), pp 166-230. London: Butterworths.

Björklund A, Lindvall O (2000) Cell replacement therapies for central nervous system disorders. Nat Neurosci 3:537-544.

Brundin P, Björklund A (1998) Survival of expanded dopaminergic precursors is critical for clinical trials. Nat Neurosci 1:537.

Brundin P, Strecker RE, Widner H, Clarke DJ, Nilsson OG, Astedt B, Lindvall O, Björklund A (1988) Human fetal dopamine neurons grafted in a rat model of Parkinson's disease: immunological aspects, spontaneous and drug-induced behavior, and dopamine release. Exp Brain Res 70:192-208.

Brundin P, Duan WM, Sauer H (1994) Functional effects of mesencephalic dopamine neurons and adrenal chromaffin cells grafted to the rodent striatum. In: Functional neural transplantation (Dunnett S, Björklund A, eds), pp 157-195. New York: Raven.

Daadi MM, Weiss S (1999) Generation of tyrosine hydroxylaseproducing neurons from precursors of the embryonic and adult forebrain. J Neurosci 19:4484-4497.

Dahlstrand J, Lardelli M, Lendahl U (1995) Nestin mRNA expression correlates with the central nervous system progenitor cell state in many, but not all, regions of developing central nervous system. Brain Res Dev Brain Res 84:109-129.

Damier P, Hirsch EC, Agid Y, Graybiel AM (1999) The substantia nigra of the human brain. II. Patterns of loss of dopamine-containing neurons in Parkinson's disease. Brain 122:1437-1448.

Frodl EM, Duan WM, Sauer H, Kupsch A, Brundin P (1994) Human embryonic dopamine neurons xenografted to the rat: effects of cyopreservation and varying regional source of donor cells on transplant survival, morphology and function. Brain Res 647:286-298.

Gerdes J, Schwab U, Lemke H, Stein H (1983) Production of a mouse monoclonal antibody reactive with a human nuclear antigen associated with cell proliferation. Int J Cancer 31:13-20.

Haque NS, LeBlanc CJ, Isacson O (1997) Differential dissection of the rat E16 ventral mesencephalon and survival and reinnervation of the 6-OHDA-lesioned striatum by a subset of aldehyde dehydrogenasepositive TH neurons. Cell Transplant 6:239-248.

Hatanaka H, Arimatsu Y (1984) Monoclonal antibodies to tyrosine hydroxylase from rat pheochromocytoma PC12h cells with special reference to nerve growth factor-mediated increase of the immunoprecipitable enzymes. Neurosci Res 1:253-263.

Hockfield S, McKay RD (1985) Identification of major cell classes in the developing mammalian nervous system. J Neurosci 5:3310-3328.

Hulpas R, Tiarks C, Reilly J, Hsidh C-C, Recht L, Quesenberry PJ (1997) In vitro cell-density dependent clonal growth of EGF-responsive murine neural progenitor cells under serum-free conditions. Exp Neurol 148:147-156.

Kalsbeek A, Voorn P, Buijs RM (1992) Development of dopaminecontaining systems in the CNS. In: Handbook of chemical neuroanatomy Vol 10 (Björklund A, Hökfelt T, Tohyama T, eds), pp. 63-112. Amsterdam: Elsevier.

Kaneko Y, Sakakibara S, Imai T, Suzuki A, Nakamura Y, Sawamoto K, Ogawa Y, Toyama Y, Miyata T, Okano H (2000) Musashi 1: an evolutionally conserved marker for CNS progenitor cells including neural stem cells. Dev Neurosci 22:138-152.

Kawaguchi A, Miyata T, Sawamoto K, Takashita N, Murayama A, Akamatsu W, Ogawa M, Okabe M, Tano Y, Goldman SA, Okano H (2001) Nestin-EGFP transgenic mice: visualization of the self-renewal and multipotency of CNS stem cells. Mol Cell Neurosci 17:259-273.

Kawano H, Ohyama K, Kawamura K, Nagatsu I (1995) Migration of dopaminergic neurons in the embryonic mesencephalon of mice. Brain Res Dev Brain Res 86:101-113.

Lindvall O (1994) Neural transplants in Parkinson's disease. In: Functional neural transplantation (Dunnett SB, Björklund A, eds), pp 103 137. New York: Raven.
Ling ZD, Potter ED, Lipton JW, Carvey PM (1998) Differentiation of mesencephalic progenitor cells into dopaminergic neurons by cytokines. Exp Neurol 149:411-423.

Lorang D, Amara SG, Simerly RB (1994) Cell-type-specific expression of catecholamine transporters in the rat brain. J Neurosci 14:4903-4914.

Lothian C, Lendahl U (1997) An evolutionarily conserved region in the second intron of the human nestin gene directs gene expression to CNS progenitor cells and to early neural crest cells. Eur J Neurosci $9: 452-462$.

Nagatsu I, Komori K, Miura K, Sakai M, Karasawa N, Yamada K (1989) Ontogeny of phenylethanolamine- $N$-methyltransferase and tyrosine hydroxylase-immunoreactive expression in the mouse anterior olfactory nucleus. Biomed Res 10:277-286.

Nagatsu T, Yamaguchi T, Rahman MK, Trocewicz J, Oka K, Hirata Y, Nagatsu I, Narabayashi H, Kondo T, Iizuka R (1984) Catecholaminerelated enzymes and the biopterin cofactor in Parkinson's disease and related extrapyramidal diseases. In: Advances in neurology, Vol 40 (Hasseler RG, Christ J F, eds), pp. 467-473. New York: Raven.

Nakao N, Frodl EM, Duan W M, Widner H, Brundin P (1994) Lazaroids improve the survival of grafted rat embryonic dopaminergic neurons. Proc Natl Acad Sci USA 91:12408-12412.

Nakao N, Ogura M, Nakai K, Itakura T (1998) Intrastriatal mesencephalic grafts affect neuronal activity in basal ganglia nuclei and their target structures in a rat model of Parkinson's disease. J Neurosci 18:1806-1817.

Nishino H, Hida H, Takei N, Kumazaki M, Nakajima K, Baba H (2000) Mesencephalic neural stem (progenitor) cells develop to dopaminergic neurons more strongly in dopamine-depleted striatum than in intact striatum. Exp Neurol 164:209-214.

Okano H, Goldman SA (2000) Identification and selection of neural progenitor cells. NeuroScience News 3:27-31.

Potter ED, Ling ZD, Carvey PM (1999) Cytokine-induced conversion of mesencephalic-derived progenitor cells into dopamine neurons. Cell Tissue Res 296:235-246.

Reynolds BA, Weiss S (1992) Generation of neurons and astrocytes from isolated cells of the adult mammalian central nervous system. Science 255:1707-1710.

Roy NS, Wang S, Jiang L, Kang J, Benraiss A, Harrison-Restelli C, Fraser RA, Couldwell WT, Kawaguchi A, Okano H, Nedergaard M, Goldman SA (2000a) In vitro neurogenesis by progenitor cells isolated from the adult human hippocampus. Nat Med 6:271-277.

Roy NS, Benraiss A, Wang S, Fraser RA, Goodman R, Couldwell WT, Nedergaard M, Kawaguchi A, Okano H, Goldman SA (2000b) Promoter-targeted selection and isolation of neural progenitor cells from the adult human ventricular zone. J Neurosci Res 59:321-331.

Sakakibara S, Imai T, Hamaguchi K, Okabe M, Aruga J, Nakajima K, Yasutomi D, Nagata T, Kurihara Y, Uesugi S, Miyata T, Ogawa M, Mikoshiba K, Okano H (1996) Mouse-Musashi-1, a neural RNAbinding protein highly enriched in the mammalian CNS stem cell. Dev Biol 176:230-242.

Sakurada K, Ohshima-Sakurada M, Palmer TD, Gage FH (1999) Nurr1, an orphan nuclear receptor, is a transcriptional activator of endogenous tyrosine hydroxylase in neural progenitor cells derived from the adult brain. Development 126:4017-4026.

Santa-Olalla J, Cardenas-Aguayo MC, Fregoso-Lomas M, Covarrubias L (2000) Positional identity is not preserved in neural precursor cells grown as neurospheres. Soc Neurosci Abstr 26:23.3.

Sauer H, Brundin P (1991) Effects of cool storage on survival and function of intrastriatal ventral mesencephalic grafts. Restor Neurol Neurosci 2:123-135.

Sawamoto K, Yamamoto A, Kawaguchi A, Yamaguchi M, Mori K, Goldman SA, Okano H (2001a) Direct isolation of committed neuronal progenitor cells from transgenic mice co-expressing spectrallydistinct fluorescent proteins regulated by stage-specific neural promoters. J Neurosci Res, in press.

Sawamoto K, Nakao N, Kobayashi K, Matsushita N, Takahashi H, Kakishita K, Yamamoto A, Yoshizaki T, Terashima T, Murakami F, Itakura T, Okano H (2001b) Visualization, direct isolation, and transplantation of midbrain dopaminergic neurons. Proc Natl Acad Sci USA, in press.

Schmidt RH, Björklund A, Stenevi U, Dunnett SB, Gage FH (1983) Intracerebral grafting of neuronal cell suspensions. III. Activity of intrastriatal nigral suspension implants as assessed by measurements of dopamine synthesis and metabolism. Acta Physiol Scand Suppl 522:19-28

Sinclair SR, Fawcett JW, Dunnett SB (1999) Dopamine cells in nigral grafts differentiate prior to implantation. Eur J Neurosci 11:4341-4348. Smidt MP, van Schaick HS, Lanctot C, Tremblay JJ, Cox JJ, van der Kleij AA, Wolterink G, Drouin J, Burbach JP (1997) A homeodomain gene Ptx3 has highly restricted brain expression in mesencephalic dopaminergic neurons. Proc Natl Acad Sci USA 94:13305-13310.

Studer L, Tabar V, McKay RD (1998) Transplantation of expanded mesencephalic precursors leads to recovery in parkinsonian rats. Nat Neurosci 1:290-295. 
Svendsen CN, Clarke DJ, Rosser AE, Dunnett SB (1996) Survival and differentiation of rat and human epidermal growth factor-responsive precursor cells following grafting into the lesioned adult central nervous system. Exp Neurol 137:376-388.

Svendsen CN, Caldwell MA, Shen J, ter Borg MG, Rosser AE, Tyers, P, Karmiol, S, Dunnett SB (1997) Long-term survival of human central nervous system progenitor cells transplanted into a rat model of Parkinson's disease. Exp Neurol 148:135-146.

Uchida N, Buck DW, He D, Reitsma MJ, Masek M, Phan TV, Tsukamoto AS, Gage FH, Weissman IL (2000) Direct isolation of human central nervous system stem cells. Proc Natl Acad Sci USA 97:14720-14725.

Wang S, Wu H, Jiang J, Delohery TM, Isdell F, Goldman SA (1998) Isolation of neuronal precursors by sorting embryonic forebrain transfected with GFP regulated by the T alpha 1 tubulin promoter. Nat Biotechnol [Erratum (1998) 16:478] 16:196-201.

Weigmann A, Corbeil D, Hellwig A, Huttner WB (1997) Prominin, a novel microvilli-specific polytopic membrane protein of the apical sur- face of epithelial cells, is targeted to plasmalemmal protrusions of non-epithelial cells. Proc Natl Acad Sci USA 94:12425-12430.

Yamaguchi M, Saito H, Suzuki M, Mori K (2000) Visualization of neurogenesis in the central nervous system using nestin promoter-GFP transgenic mice. NeuroReport 11:1991-1996.

Ye W, Shimamura K, Rubenstein JL, Hunes MA, Rosenthal A (1998) FGF and Shh signals control dopaminergic and serotonergic cell fate in the anterior neural plate. Cell 29:755-766.

Zigova T, Pencea V, Betarbet R, Wiegand SJ, Alexander C, Bakay RA, Luskin MB (1998) Neuronal progenitor cells of the neonatal subventricular zone differentiate and disperse following transplantation into the adult rat striatum. Cell Transplant 7:137-156.

Zimmerman L, Parr B, Lendahl U, Cunningham M, McKay R, Gavin B, Mann J, Vassileva G, McMahon A (1994) Independent regulatory elements in the nestin gene direct transgene expression to neural stem cells or muscle precursors. Neuron 12:11-24. 